\title{
Use of immunohistochemical methods in the differential diagnosis between primary cerebellar haemangioblastoma and metastatic renal carcinoma
}

\author{
D R GOULDESBROUGH, * J E BELL, $\dagger$ A GORDON†
}

From the *Department of Pathology, University of Edinburgh Medical School, Edinburgh and the $\dagger$ Neuropathology Laboratory, Western General Hospital, Edinburgh, Scotland

SUMMARY The potential role of immunohistochemistry in making the distinction between primary cerebellar haemangioblastoma and metastatic renal carcinoma was investigated by examining the reaction pattern of 10 cerebellar haemangioblastomas (seven women, three men, aged $20-40$ years) and 10 primary renal carcinomas (six men, four women, aged 49-82 years) to a panel of epithelial, glial, and neural/neuroendocrine antisera. The tumour cell membranes of the renal carcinomas stained strongly with epithelial membrane antigen (EMA); membrane staining was totally absent in the haemangioblastomas. Strong neurone specific enolase (NSE) and S100 staining were also seen in haemangioblastomas but were more variable than EMA staining in renal carcinomas.

It is concluded that a panel of antisera is required to distinguish between histologically similar areas in primary haemangioblastomas and metastatic renal carcinomas, and that while complementing conventional histological techniques, new problems of interpretation result which must be taken into account.

The differential diagnosis of "clear cell" tumours of the posterior cranial fossa has long been recognised as being very difficult.' The particular difficulty presented by such lesions at this site is in distinguishing between a primary haemangioblastoma and a metastasis from a primary "clear cell" renal carcinoma. ${ }^{23}$ Textbook descriptions of both these entities are available but, for practical diagnostic purposes, conventional histological techniques may not be sufficient to distinguish between them. ${ }^{4}$

The advent of immunohistochemical techniques and the subsequent refinement of monoclonal antibody technology have provided powerful analytical tools for experimental and diagnostic work. We investigated the role of these techniques in supplementing conventional methods in the diagnosis of the posterior cranial fossa "clear cell" tumour.

\section{Material and methods}

HAEMANGIOBLASTOMA

Ten cases of posterior cranial fossa haemangioblastoma were selected from the recent biopsy files of

Accepted for publication 17 March 1988 the neuropathology laboratory at the Western General Hospital, Edinburgh. No evidence of a renal lesion was present in any case either at presentation or on subsequent follow up. There were seven men and three women, the average age of the patients being 33 years (range 20-45). Nine of the 10 cases were of a tumour within the cerebellum and one was of a tumour on the posterior surface of the medulla oblongata. All of these tumours at operation were highly vascular, seven were solid, and three were cystic with macroscopic nodules in their walls.

\section{RENAL CARCINOMA}

Ten cases of nephrectomy for primary renal carcinoma were selected from the recent files of the department of pathology at Edinburgh University Medical School. There were six men and four women, the average age of the patients being 66 years (range 49-82). Six of the tumours were situated at the upper pole of the kidney, three at the lower, and one centrally. All were roughly spherical with a variegated yellowish white cut surface with focal necrosis and haemorrhage. Capsular invasion was seen in five and spread to the lumen of a renal vein was present in two.

Paraffin wax sections from the tumour in both groups were stained with haematoxylin and eosin, 
Table 1 Antisera used for immunoperoxidase staining

\begin{tabular}{|c|c|c|c|}
\hline Antibody & Supplier & $\begin{array}{l}\text { Poly }(P) \\
\text { Monoclonal } \\
(M)\end{array}$ & Dilution \\
\hline $\begin{array}{l}\text { Neurone specific } \\
\text { enolase (NSE) }\end{array}$ & $\begin{array}{l}\text { Dakopatts } \\
\text { (A589) }\end{array}$ & $\mathbf{P}$ & $1 / 300$ \\
\hline $\begin{array}{l}\text { S100 protein } \\
\text { (S100) }\end{array}$ & $\begin{array}{l}\text { Dakopatts } \\
\text { (Z311) }\end{array}$ & $\mathbf{P}$ & $1 / 50$ \\
\hline $\begin{array}{l}\text { Factor VIII related } \\
\text { antigen (F VIII RAG) }\end{array}$ & $\begin{array}{l}\text { Dakopatts } \\
\text { (A082) }\end{array}$ & $\mathbf{P}$ & $1 / 100$ \\
\hline $\begin{array}{l}\text { Glial fibrillary } \\
\text { acidic protein (GFAP) }\end{array}$ & $\begin{array}{l}\text { Dakopatts } \\
\text { (X334) }\end{array}$ & $\mathbf{P}$ & $1 / 400$ \\
\hline $\begin{array}{l}\text { Epithelial membrane } \\
\text { antigen (EMA) }\end{array}$ & Dakopatts & $\mathbf{M}$ & $1 / 40$ \\
\hline $\begin{array}{l}\text { Cytokeratin PKK 1 } \\
\text { (PKK1) }\end{array}$ & $\begin{array}{l}\text { Labsystems } \\
(6400201)\end{array}$ & $\mathbf{M}$ & $1 / 100$ \\
\hline $\begin{array}{l}\text { Cytokeratin CAM } 5 \cdot 2 \\
\text { (CAM 5.2) }\end{array}$ & & $\mathbf{M}$ & $1 / 100$ \\
\hline
\end{tabular}

periodic acid schiff (PAS), periodic acid schiff following digestion with diastase (PAS/DIAS) (for intracytoplasmic glycogen), and silver impregnation for reticulin.

Similar sections, dried at low temperature $\left(50^{\circ} \mathrm{C}\right)$, were reacted with the panel of antisera detailed in table 1 .

A standard PAP technique was used for the polyclonal antisera ${ }^{5}$ and an indirect method with rabbit anti-mouse peroxidase conjugate for the monoclonal antisera. ${ }^{6}$

The histological and histochemical appearances of each series of tumours were examined for their resemblance to the classic "textbook" appearance and to each other.

The distribution pattern of the immunohistochemical reaction was noted and the intensity of the reaction semiquantitatively scored from (0) to $(+++)$.

\section{Results}

\section{HISTOCHEMISTRY}

Haemangioblastoma All cases were composed of thin walled vascular channels separated by trabeculae of stromal cells (fig 1). The endothelial cells lining these channels were mostly thin and flattened although focally they were plump with pale vesicular nuclei. The stromal cells were polygonal with central nuclei and pale, occasionally vacuolated cytoplasm. A minor degree of nuclear pleomorphism was seen in the stromal cells of some of these tumours but mitotic activity was inconspicuous.

Positive intracytoplasmic granular staining for glycogen was present in seven of the 10 haemangioblastomas but varied widely in distribution and intensity. Silver impregnation outlined blood vessels and aggregates of stromal cells but little pericellular reticulin was demonstrable.
Renal carcinoma All cases showed some histological variability. The prominent "clear cell" areas were interspersed with areas of tubular or papillary configuration (fig 2). A highly vascular stroma was present throughout, the endothelial cells being mainly flattened but occasionally plump and polygonal. Mild, focally moderate, nuclear pleomorphism was exhibited by all tumours but mitotic activity was inconspicuous.

Intracytoplasmic glycogen was again present in most tumours (nine of 10) but its varied distribution produced a substantial overlap with that seen in the haemangioblastomas. A similar reticulin pattern was also seen, blood vessels and tumour cell islands being outlined.

\section{IMMUNOHISTOCHEMISTRY}

Haemangioblastoma The reaction patterns obtained are summarised in table 2. The endothelial cells exhibited strong, diffuse granular staining with factor VIII related antigen (F VIII RAG). The stromal cells reacted strongly, but in a focal manner, with nonspecific enolase and in some, but not all cases, with

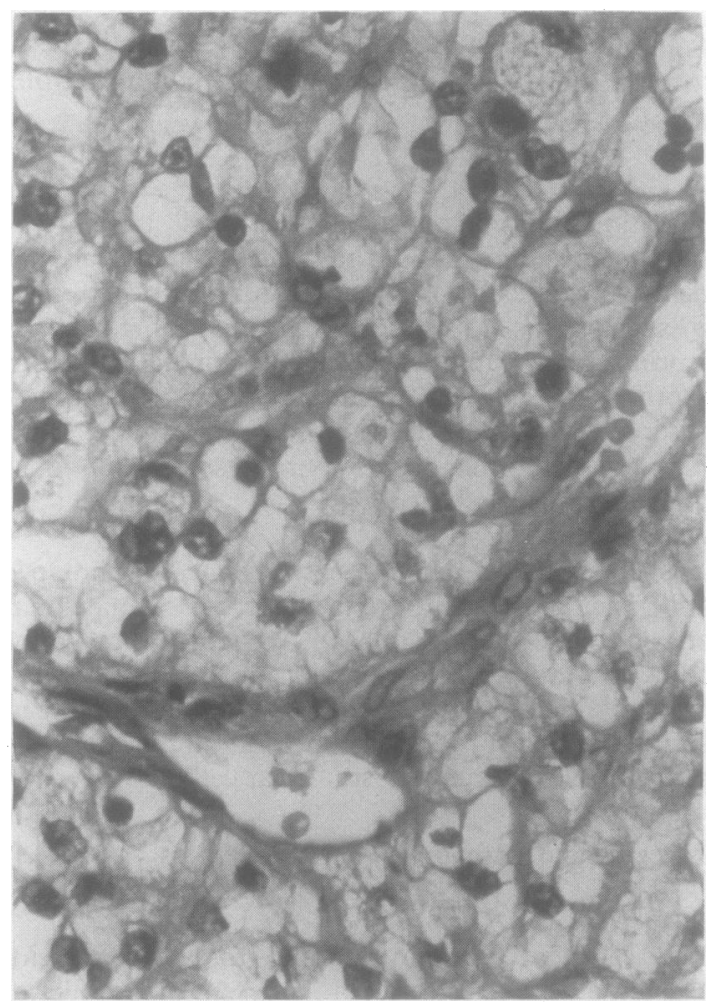

Fig 1 Section of haemangioblastoma to show vascular framework and plump, clear stromal cells. (Haematoxylin and eosin.) 


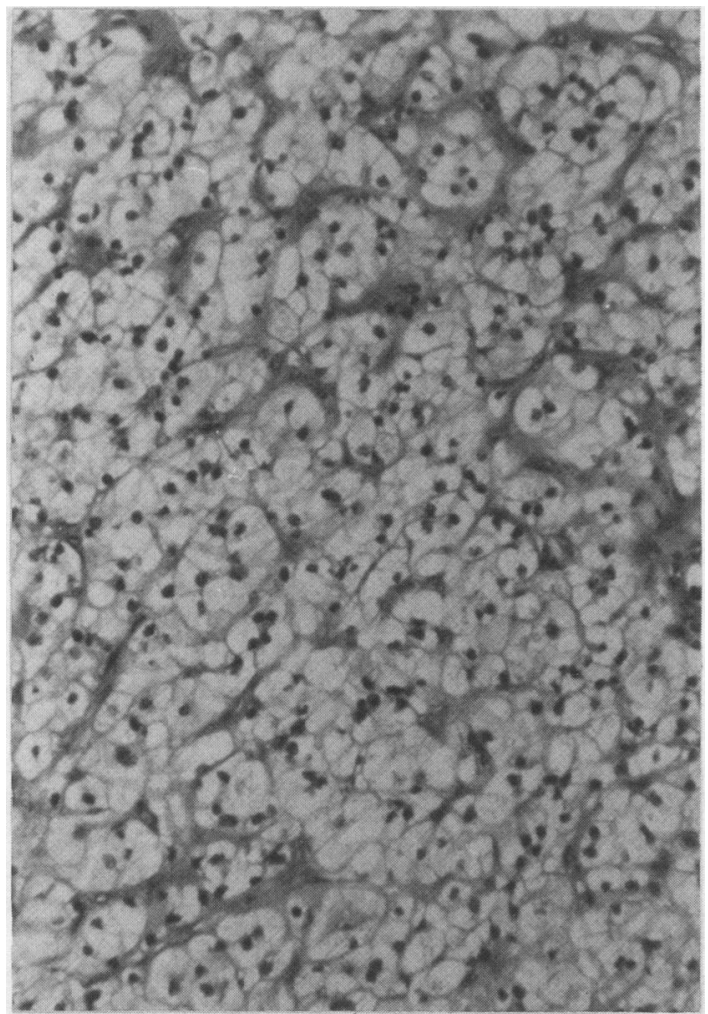

Fig 2 "Classic" clear cell area within a renal carcinoma (Haematoxylin and eosin.)

S100. Occasional, peripherally placed glial fibrillary acidic protein (GFAP) positive cells were seen, especially where an interface between tumour and normal brain was present. Focal, very weak reaction with epithelial membrane antigen was seen in the stromal cell cytoplasm in some cases, but no membrane staining was shown (fig 3).

Renal carcinoma The reaction patterns obtained are summarised in table 3. Strong, diffuse granular staining was again found for F VIII RAG in endothelial cells. Focal, cytoplasmic F VIII RAG staining was present in some tumour cells, especially adjacent to blood vessels.

All cases showed strong but focal staining of tumour cell membranes with epithelial membrane antigen (EMA) (fig 4). This antibody also reacted in a patchy distribution with the tumour cell cytoplasm in most cases.

Tumour cell membrane and cytoplasmic cytokeratin positivity was present but was variable and seen only in a few cases; CAM5.2 reactivity was generally more pronounced than PKK1.
Table 2 Immunohistochemistry of haemangioblastomas

$\begin{array}{llll}\hline & & \multicolumn{2}{l}{\text { Stromal cell }} \\$\cline { 3 - 4 } \text {$\left.Antibody } & \begin{array}{l}\text { Endothelial cell } \\ \text { cytoplasm }\end{array} & \text { Membrane } & \text { Cytoplasm } \\ \hline \text { PKK1 } & - & - & - \\ \text { CAM 5.2 } & - & - & - \\ \text { EMA } & - & - & +1-5 / 9 \\ \text { NSE } & - & - & +++9 / 9 \\ \text { GFAP } & - & - & +1-4 / 9 \\ \text { F VIII RAG } & +++9 / 9 \text { D } & - & +++5 / 9\end{array}\right\}$

$\mathbf{F}=$ Focal staining $\quad \mathrm{D}=$ Diffuse staining

\section{Discussion}

To assess the role of immunohistochemistry in this difficult differential diagnosis, we chose to study primary haemangioblastomas and primary renal carcinomas. Andrew and Gradwell ${ }^{7}$ examined the problem using central nervous system metastases of renal carcinoma. They point out that some of their cases were originally diagnosed as haemangioblastomas, the diagnosis being changed on subsequent discovery of a primary renal carcinoma. To attempt to exclude this difficulty we used haemangioblastomas

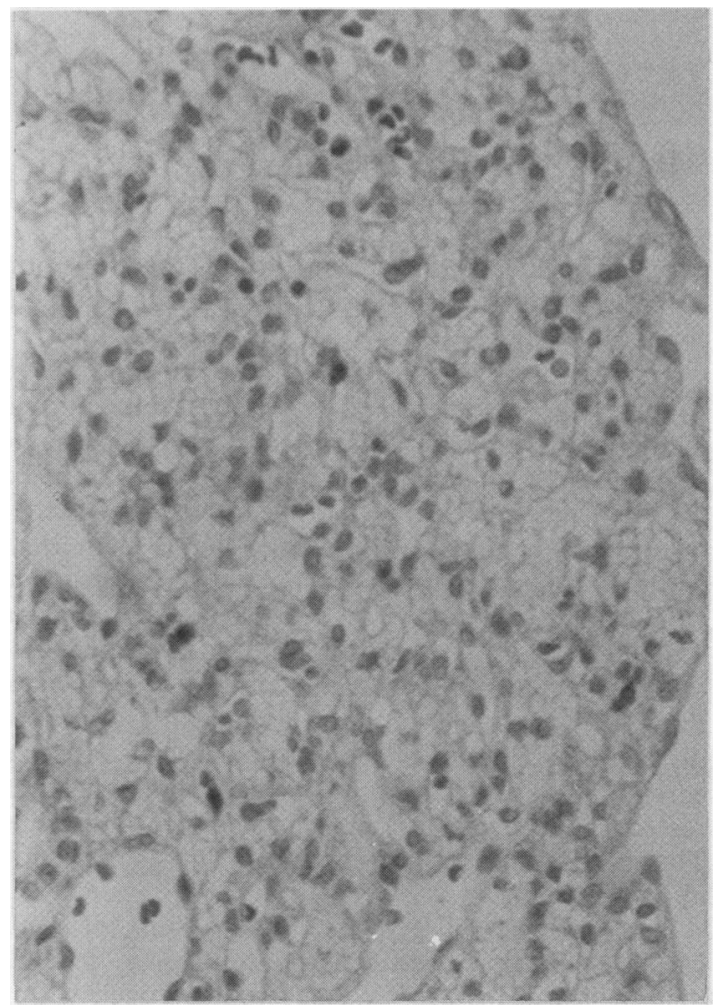

Fig 3 Section of a haemangioblastoma stained for EMA and showing absence of membrane staining. 


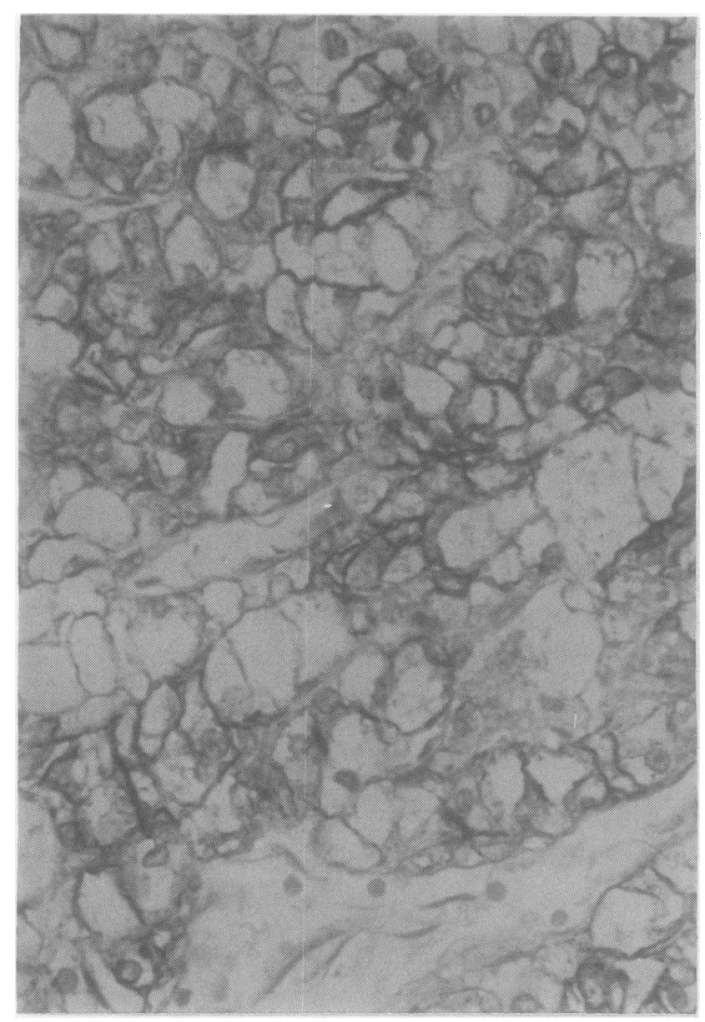

Fig 4 Strong membrane staining for EMA in a renal carcinoma.

with no evidence of a concomitant renal lesion initially, or on clinical follow up, and primary renal carcinomas.

The histological findings in our cases serve to confirm the problems faced using conventional methods. The renal carcinomas showed variable morphology with papillary and tubular areas admixed with a "classic" clear cell appearance. This latter histological pattern was indistinguishable from areas within the haemangioblastomas and vice versa. No valid distinction could be made between these areas on cell morphology, arrangement, mitotic activity, degree of pleomorphism or vascular pattern. Isaac et al thought it possible on morphological grounds to distinguish between a metastatic deposit of renal carcinoma at the site of previous haemangioblastoma resection and a recurrence of the haemangioblastoma. This may be impossible using histological examination alone.

The presence of glycogen within cells of renal carcinomas has received attention as a possible distinguishing feature. ${ }^{8}$ We showed glycogen within the cytoplasm of cells of both groups of tumours. The amount present varied widely and no significant
Table 3 Immunohistochemistry of renal carcinomas

\begin{tabular}{|c|c|c|c|c|c|}
\hline \multirow[b]{2}{*}{ Antibody } & \multirow{2}{*}{$\begin{array}{l}\text { Endothelial } \\
\text { cell } \\
\text { cytoplasm }\end{array}$} & \multicolumn{4}{|l|}{ Tumour cells } \\
\hline & & Membrane & & Cytoplasm & \\
\hline $\begin{array}{l}\text { PKK1 } \\
\text { CAM 5·2 } \\
\text { EMA } \\
\text { NSE } \\
\text { GFAP } \\
\text { Factor VIII } \\
\text { S100 }\end{array}$ & 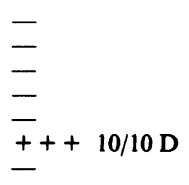 & $\left.\begin{array}{lr}+/- & 1 / 10 \\
++ & 3 / 10 \\
+t & 10 / 10 \\
+ & 7 / 10\end{array}\right\}$ & $\mathbf{F}$ & $\left.\begin{array}{ll}+/- & 3 / 10 \\
++ & 5 / 10 \\
++ & 9 / 10 \\
+ & 4 / 10 \\
+ & \\
+t+9 / 10 \\
+ & 3 / 10\end{array}\right\}$ & \\
\hline
\end{tabular}

$\mathbf{F}=$ Focal staining $\quad \mathrm{D}=$ Diffuse staining

difference could be detected between the groups on this basis. The variable effects of fixation and processing on PAS positivity are also relevant here. Similarly, the reticulin pattern outlined the vascular framework and tumour cell islands in both samples.

The immunohistochemistry yielded interesting and potentially useful findings. The striking difference between the two groups was that in the present series in the tumour cell membranes the renal carcinomas stained strongly with EMA; membrane staining was totally absent in the haemangioblastomas. This strong membrane staining tended to be focal and might thus be missed in a small biopsy specimen but the technique does seem to yield a clear cut distinction between the two lesions.

No staining was observed in haemangioblastomas with the two cytokeratins used. The stronger and more widespread positivity in renal carcinomas with CAM 5:2 rather than PKK1 broadly concurs with other workers' experience. ${ }^{9}$ The absence of staining in half of the renal carcinomas limits the value of a negative reaction.

Strong neurone specific enolase positivity in all haemangioblastomas was a positive pointer to that diagnosis and agrees with other workers' findings, ${ }^{10}$ but the presence of weak cytoplasmic staining in some renal carcinomas made this distinction less than absolute. Likewise, strong S100 positivity indicated a haemangioblastoma but this was not seen in every case.

The focal positive reaction for GFAP in a few haemangioblastomas was of interest. The cells so stained lay peripherally, especially where an interface between tumour and brain was present in the biopsy specimen. This phenomenon has been plausibly ascribed to the presence of reactive astrocytes or to the uptake of antigen by tumour cells. ${ }^{112}$ It may be this that we saw rather than true tumour reactivity.

No detectable difference in endothelial F VIII RAG reactivity was shown between the two types of tumour but the striking positivity of the renal carcinoma cells with this antibody was of interest and contrasted with the haemangioblastoma stromal cell. It was difficult to determine whether this represented true expression of 
the antigen by the tumour cells or was again uptake of shed antigen; the accentuation of the tumour cell staining around blood vessels may indicate the latter.

We conclude that immunohistochemistry has a part to play in distinguishing between histologically similar areas in primary haemangioblastomas and metastatic renal carcinomas. It was clear that a panel of antisera was required in this diagnostic problem. Our findings regarding EMA reactivity were in agreement with those of Andrew and Gradwell, ${ }^{7}$ but we emphasise that the focal nature of the positive staining suggested that supportive evidence should be sought using other antisera. Cytokeratin reactivity in renal carcinomas and neurone specific enolase and $\mathrm{S} 100$ reactivity in haemangioblastomas would corroborate this.

The use of these antisera thus complemented conventional histological techniques but produced new problems of interpretation which must be recognised and taken into account.

Grateful thanks go to Mr W Shade, Mr D Cossar, and Mr A Smith for technical assistance and to Mrs Margo Boyle for the swift and efficient typing of the manuscript.

\section{References}

1 Melman KL, Rosen SW. Lindau's disease: review of the literature and study of a large kindred. Am J Med 1964;36:595-617.

2 Isaac F, Schoen I, Walker P. An unusual case of Lindau's disease. Cystic disease of the kidneys and pancreas with renal and cerebellar tumours. Am J Roent 1956:75:912-20.

3 Rubinstein LJ. Tumours and malformations of the blood vessels.
In: Tumours of the central nervous system. Washington, DC. Armed Forces Institute of Pathology. 1972:239-40.

4 Epstein JI, White CL, Mendelsohn G. Factor VIII related antigen and GFAP immunoreactivity in the differential diagnosis of CNS haemangioblastomas. Am J Clin Pathol 1984;81:285-92.

5 Sternberger LA, Hardy PH, Cuculis JJ. The unlabelled antibody enzyme method of immunohistochemistry. $J$ Histochem Cytochem 1970;18:315-33.

6 Salter DM, Krajewski AS, Dewar AE. Immunohistochemical staining of non-Hodgkin's Lymphoma with monoclonal antibodies specific for the leucocyte common antigen. J Pathol 1985;146:345-53.

7 Andrew SM, Gradwell E. Immunoperoxidase labelled antibody staining in differential diagnosis of CNS haemagioblastomas and CNS metastases of renal carcinomas. J Clin Pathol 1986:39:917-19.

8 Burger PC, Vogel FS. In: Surgical pathology of the nervous system. 3rd Edition. New York: John Wiley and Sons, 1982.

9 Fleming S, Symes CE. The distribution of cytokeratin antigens in the kidney and in renal tumours. Histopathol 1987;11:157-70.

10 Ismail SM, Jasani B, Cole G. Histogenesis of haemangioblastomas: an immunohistochemical and ultrastructural study in a case of von Hippel-Lindau Syndrome. J Clin Pathol 1985;38:417-21.

11 Deck JHN, Rubinstein LJ. GFAP in stromal cells of some capillary haemangioblastomas: significance and possible implication of an immuno-peroxidase study. Acta Neuropathol 1981;54:173-81.

12 Rubinstein LJ. Immunohistochemical signposts-not markersin neural tumour differentiation. Neuropathol Appl Neurobiol 1986;12:523-37.

Requests for reprints to: $\operatorname{Dr}$ D R Gouldesbrough, Department of Pathology, University Medical School, Teviot Place, Edinburgh EH8 9AG, Scotland. 